

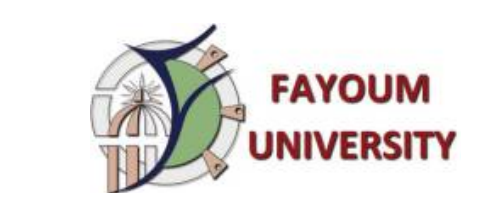

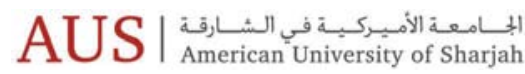

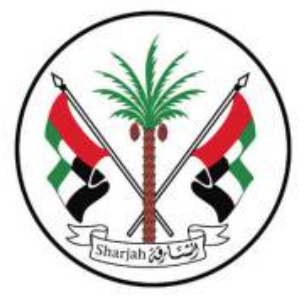

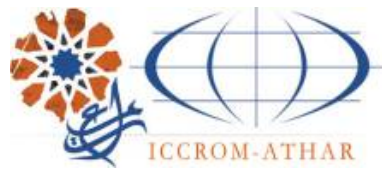

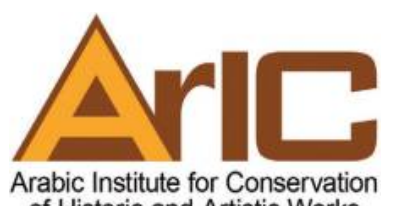
Arabic Institute for Conservation
of Historic and Artistic Works

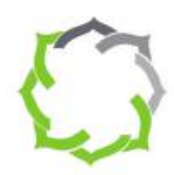

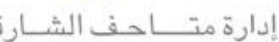

Sharjah Museums Department

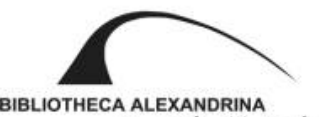

هكتبة الإسطنسوية

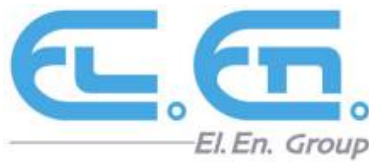

Laser Technologies

SWPecial

You can sign up for selected content free of charge, and also sign up for table of contents alerts at www.maneyonline.com/sic 


\title{
Collections care scenario appraisal for painting canvases at Museu Nacional d'Art de Catalunya, Barcelona, Spain
}

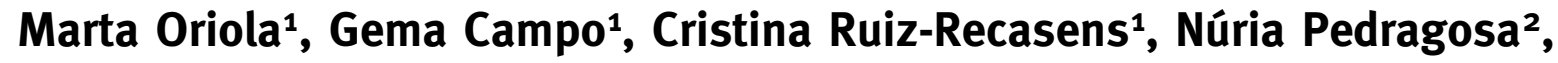 \\ Matija Strlič ${ }^{3}$
}

\author{
${ }^{1}$ Faculty of Fine Arts, Conservation Section, University of Barcelona, Barcelona, Spain, ${ }^{2}$ Conservation \\ Department, Museu Nacional d'Art de Catalunya, Barcelona, Spain, ${ }^{3}$ Institute for Sustainable Heritage, \\ University College London, London, UK
}

\begin{abstract}
We surveyed the canvas of 31 paintings from the collection of the Museu Nacional d'Art de Catalunya, Barcelona, Spain, using non-destructive near infrared spectroscopy (NIR) in order to determine the $\mathrm{pH}$ and degree of polymerisation (DP) of the canvas supports. The data showed that the canvases, all from 1890 to 1910, are acidic (average pH 5.1 \pm 0.4 ) and fairly degraded (DP $710 \pm 260$ ). Using the doseresponse function for cellulosic materials with $\mathrm{pH}, \mathrm{DP}, \mathrm{T}$, and relative humidity $(\mathrm{RH})$ as inputs, the rate of degradation can be calculated, as well as the period of time until the point when the canvases become so fragile that their handling could lead to mechanical damage and thus risk the integrity of paint layers. On the basis of the survey data, we calculated isochrone plots as well as demographic curves for the collection. Using these, we explored a number of conservation management scenarios and compared them with the expected rate of degradation under current average environmental conditions $\left(21^{\circ} \mathrm{C}, 58 \%\right.$ $\mathrm{RH})$. At these conditions, it is predicted that the average canvas will become fragile and might require interventive treatment in ca. 140 years. However, if the storage temperature is decreased, or if the canvases are deacidified, the period of time until treatment becomes necessary can be considerably increased. As a separate case study we also present a survey of the canvas of The Woman in Hat and Fur Collar (Marie-Thérèse Walter) by Pablo Picasso. The $\mathrm{pH}$ and DP of this canvas was determined in 15 sampling points, the averages being pH $5.6 \pm 0.2$ and DP $1700 \pm 320$, which allowed us to calculate the isochrone plot for this canvas.
\end{abstract}

Keywords: NIR spectrometry, pH, DP, Canvas degradation, Lifetime prediction, Paintings

\section{Introduction}

In a traditional easel painting, the canvas support is made of plant-derived cellulosic fibres. In a recent survey of a large sample set of ca. 200 historic canvases, the majority was found to have $\mathrm{pH}$ of $4.5-6.0$, i.e. less than neutral (Oriola et al., 2011). Acidity in the environment of a cellulose macromolecule is well known to catalyse its hydrolytic breakdown, thus decreasing its degree of polymerisation (DP, the number of monomers in a macromolecule) (Zou et al., 1996; Strlič \& Kolar, 2005). Fibres with a

Correspondence to: Marta Oriola, Facultat de Belles Arts, C/ Pau Gargallo 4 08028 Barcelona, Spain. Email: martaoriola@ub.edu; Matija Strlič, Institute for Sustainable Heritage, University College London, Central House, 14 Upper Woburn Place, London WC1H ONN, UK. Email: m.strlic@ucl.ac.uk lower DP are known to have lower mechanical resistance thus reducing the fitness of the textile to be used (Zou et al., 1996).

Painting canvases with a DP of ca. 600 can be considered to be at the upper boundary of the 'very fragile' condition category (Oriola et al., 2011). In the survey of 35 degraded canvas samples carried out by 17 internationally renowned paintings conservators, it was established (with a remarkable level of agreement) that such canvases are fragile to the point where they 'cannot be stretched without reinforcement' and 'excessive stress is not advisable'. Such canvases could be considered to be at high risk of tearing and similar mechanical damage during handling (relocation of a painting, transportation to exhibitions, etc.), thus requiring resource-intensive interventive treatment. 
The time until fitness for use is lost (useful lifetime) of a canvas can be managed either by controlling environmental conditions or by alteration of the chemical properties of a canvas. The addition of a deacidification agent counteracts the acidity of a canvas and delays its chemical degradation (Poggi et al., 2013) and therefore its fragility (Seves et al., 2000). This is not a frequently used procedure, although a reassessment of its conservation cost-benefit might be timely.

Environmental management of paintings collections, on the other hand, is (understandably so) geared towards conservation of the paint layer. Here, particularly for mixed (canvas and panel) and framed collections, the concerns lie elsewhere: adhesion of paint, gilding, and gesso layers, as well as mechanical stability of wooden parts, are managed by suitably controlling fluctuations of relative humidity (RH) (PAS198, 2012), whereas the chemical stability of canvases is seen as a secondary concern. However, both fluctuations and long-term averages of environmental parameters can be managed so that preservation is optimised.

The time until the fitness of a canvas to support the paint layer is reduced to a state when the risk of mechanical damage is unacceptable (Strlič et al., 2013), is determined by the rate of its degradation. There is ample evidence in the literature that the degradation rate of cellulosic materials is affected by temperature (T) and RH (Sebera, 1994). A recent Collections Demography project re-examined the available experimental evidence and quantitatively demonstrated how the rate of degradation of cellulosic materials is affected by material acidity (Strlič et al., 2015). A dose-response function describing this dependence was calculated and a new isoperm for cellulosic materials was presented.

On the other hand, it can be assumed that photodegradation is negligible in the majority of cases, since in easel paintings the canvas is usually protected from light. Additionally, in post-industrial environments the degradative effects of outdoor pollutants $\left(\mathrm{NO}_{2}\right.$ and $\left.\mathrm{SO}_{2}\right)$ and even of indoor pollutants (acetic acid) can be assumed to be of minor importance in comparison with $T, \mathrm{RH}$, and inherent acidity (Menart et al., 2014).

Using the knowledge of degradation of cellulosic materials available in the literature, it should therefore be possible to predict the distribution of rates of degradation of canvases in a collection, as long as we know the distribution of $\mathrm{pH}$ and DP. This data can be collected using near infrared spectroscopy (NIR), a non-destructive analytical tool that can easily be used in a non-laboratory environment as it requires no sample preparation and no sampling (Oriola et al., 2011).

NIR spectroscopy was first used to survey a collection of painting canvases non-destructively in the
Teatre-Museu Dalí in Figueres, Spain (Oriola et al., 2014). The DP and acidity of 12 canvases were determined using this technique, based on the same principle as previously used for historic paper (Trafela et al., 2007), historic textiles (Richardson et al., 2008), photographs (Fenech et al., 2013), and other types of collections. The principle is based on multivariate analysis of spectral data and method calibration based on a set of known and wellcharacterised physical samples. However, an important limitation of this method is that it can only be used for objects that are as similar to the calibration set as possible.

In this work, the developed NIR method has been applied to a collection of canvas paintings from the Museu Nacional d'Art de Catalunya, Barcelona, Spain. The obtained survey data $(\mathrm{pH}$ and $\mathrm{DP}$ values) was analysed using the Collections Demography dose-response function for cellulosic materials to provide evidence-based advice for conservation management of painting canvases.

\section{Methodology}

\section{Collection survey}

Using the previously developed methodology based on NIR spectroscopy of painting canvases (Oriola et al., 2011, 2014), pH and DP were determined for 31 canvas paintings by Catalan painters, from 1890 to 1910, at the Museu Nacional d'Art de Catalunya, Barcelona, Spain (MNAC) (Supplementary material 1). A painting by Pablo Picasso from 1937 was also analysed using this technique. From the material point of view, the canvases from this collection are contemporary with the ca. 200 canvas samples used for method calibration, the $\mathrm{pH}$ of which was determined using a cold-extraction method, while DP was measured using viscometry (Oriola et al., 2011). The majority of these calibration samples were from the nineteenth to the twenty-first century and from Catalonia, therefore of a very similar provenance to the canvases used in the survey. Consequently, the NIR spectroscopic method is likely going to give reliable data.

Since the surveyed paintings were selected on the basis of age, provenance, absence of any previous conservation treatments, and availability, the survey cannot be considered to be random, and thus representative of the larger collection. However, the selection restrictions were necessary in order to obtain collection data to be used to develop conservation guidance: a diverse collection of differently degraded and untreated real historic canvases.

\section{NIR measurements}

The NIR method for determination of $\mathrm{pH}$ and DP of historic canvases as developed in previous research 
(Oriola et al., 2014) was used in the survey (errors of prediction being \pm 0.4 for $\mathrm{pH}$ and \pm 270 for DP determination). The spectra (100 averaged spectra per measurement spot) were taken at the back of a painting using a LabSpec 5000 NIR spectrometer equipped with fibre optics and a custom-made attachment for spectral collection in the $45^{\circ} / 45^{\circ}$ geometry. The diameter of the measured spot was ca. $2 \mathrm{~mm}$. Multivariate analysis of data (partial least squares regression) and prediction of $\mathrm{pH}$ and $\mathrm{DP}$ was carried out using Grams software (Thermo Scientific). Values of $\mathrm{pH}$ were obtained for all canvases, while DP for three canvases (Cat. nos. 004.660, 004.631, 011.382) was not, due to failed statistical tests (Mahalanobis distance $>3$ ) indicating low reliability of these predictions. Several measurements were made per canvas, typically up to 7 , and the average is reported.

Using the canvas identification algorithm based on linear discriminant analysis of NIR spectra (Oriola et al., 2014), bast, cotton, and jute fibres were identified, however, out of the 31 surveyed paintings, only 3 were made of jute and 3 were made of cotton fibres, the rest were all made of bast fibres.

\section{Isoperm and isochrone calculations}

The Collections Demography dose-response function for degradation of cellulosic materials was used (Strlič et al., 2015) to calculate isoperms - lines connecting pairs of $T$ and $\mathrm{RH}$ values at which the rate of degradation or permanence of a material is equal (Sebera, 1994). However, since the Collections Demography function reflects not only $T$ and water content (which depends on $\mathrm{RH}$ ), but also $\mathrm{pH}$ of the material, isoperms based on this function need to reflect the $\mathrm{pH}$ of actual canvases.

Namely, as is well known, a reference permanence is needed in the calculation of isoperms. In Sebera's work, this was calculated for $20^{\circ} \mathrm{C}$ and $50 \% \mathrm{RH}$, but we need to note that his data were developed for acidic paper though of course at the time, this was not considered as an input in the calculations, as a suitable dose-response function did not exist at that point. In this work, however, we calculated isoperms for the actual MNAC collection, so it made sense to take the reference permanence as that of an average canvas, i.e. $\mathrm{pH} 5.1,20^{\circ} \mathrm{C}$, and $50 \% \mathrm{RH}$.

Using the threshold DP at which the risk of mechanical damage to canvas is considered to be substantial (loss of fitness for use), isochrones can be calculated. These combine pairs of $T$ and $\mathrm{RH}$ with equal expected time until loss of fitness for use. In addition to dependence on $\mathrm{pH}$, isochrones also depend on the starting DP, which is why two isochrone plots have been calculated, for the average DP and $\mathrm{pH}$ as determined in the MNAC survey, and for the same DP and $\mathrm{pH} 8$, representing the stability of hypothetically deacidified canvas. All data analysis was carried out using Origin Pro 9.0.

\section{Results}

\section{Museu Nacional d'Art de Catalunya survey}

The survey revealed that the paintings from MNAC, all of which were from 1890 to 1910 on canvas which has not undergone any interventive treatments as yet, are appreciably degraded, considering that the starting DP of new linen canvas was measured to be as high as 6600 (Oriola et al., 2012). In contrast, the average $\mathrm{pH}$ of the surveyed canvases was $5.1 \pm 0.4$ and the average DP was $710 \pm 260$ (Fig. 1). The frequency plots also show distributions of $\mathrm{pH}$ and $\mathrm{DP}$ peaking around average values tailing off towards lower $\mathrm{pH}$ and higher DP.

It might be of interest to speculate why the values are so low: namely, if the value of DP of canvas at the point of production was a multiple of 1000 , then the average DP of 710 must be a reflection of extensive degradation the canvases have already undergone. Similarly, given the low $\mathrm{pH}$ value and again considering that fresh linen has a neutral $\mathrm{pH}$, acidification
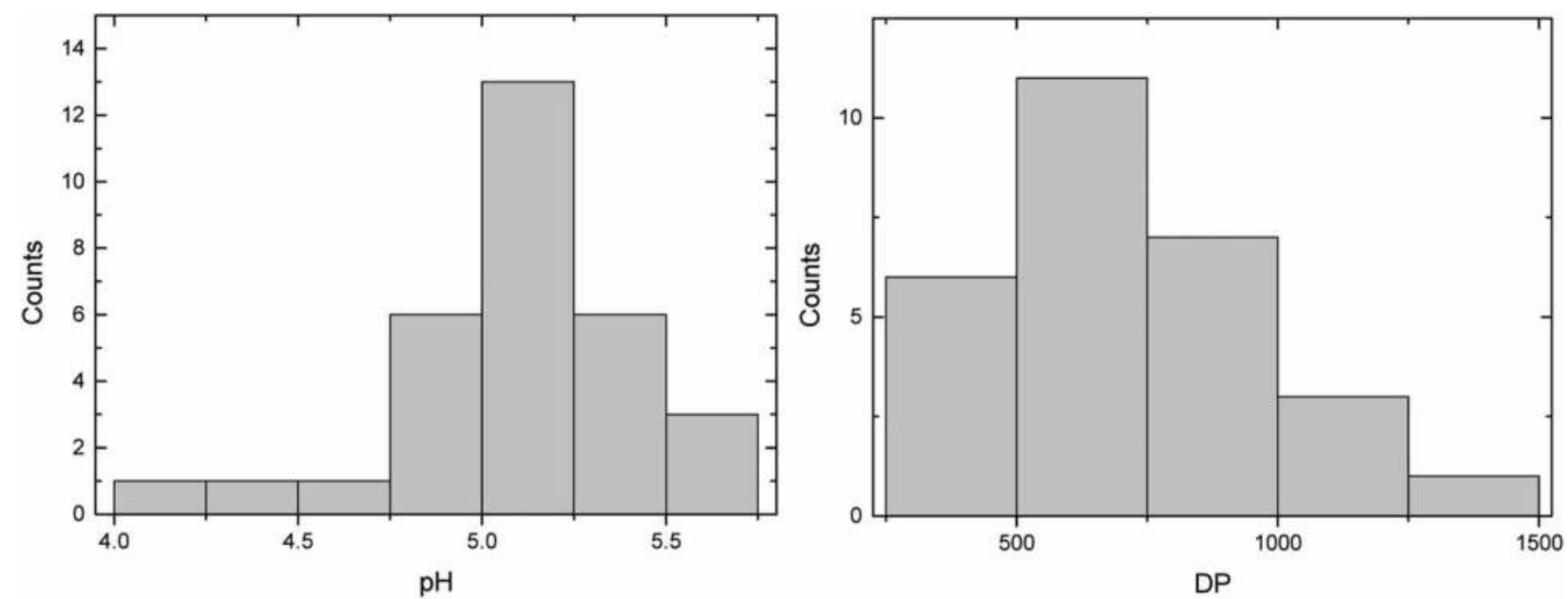

Figure 1 Frequency plots for $\mathrm{pH}(n=31)$ and DP $(n=28)$ distribution for the surveyed paintings from the MNAC collection. 
must have taken place either by (i) absorption of acidic atmospheric pollutants, (ii) through penetration of oils or varnishes from the front of a painting into the canvas and their oxidation which yields acidic products such as carboxylic acids, (iii) oxidative degradation of the cellulosic fibres themselves, or (iv) use of products such as acidified (hardened) animal glues or similar. In either case, the paintings have survived the period of Catalan industrialisation, whereas in post-industrial environments there is now a relatively much cleaner environment in comparison with the recent past (Brimblecombe \& Grossi, 2009). It is therefore safe to assume that environmental pollution is not going to represent a major source of acidification in the near future. Local staining and discolouration does not seem to result in significantly higher local acidity either (Oriola et al., 2014), which would mean that future acidification is likely going to be a consequence of natural degradation processes inherent to canvas.

It is of interest to compare MNAC averages with the data obtained from the survey of 12 Dalí paintings from Teatre-Museu Dalí, Figueres, Spain (Oriola et al., 2014). The $\mathrm{pH}$ averages for the Dalí paintings were $5.6 \pm 0.4$, which indicates less acidification which translates into less degradation as well (DP $960 \pm 350$ ). The differences between the two survey data could result from different starting acidity of the materials used or different environmental histories of the collections. Additionally, the surveyed Dalí canvases are all younger (1924-1968) than the surveyed MNAC canvases (1890-1910), which should result in more degradation of the latter.

The survey data itself, while of significance, does not allow for any conclusions on what the optimal conservation management strategies could be. To do this, we need to predict how different environmental conditions or conservation treatments will affect canvas degradation in the future, and compare the outcomes.

\section{Isoperm}

The isoperm plot for the MNAC collection, calculated using the Collections Demography dose-response function for cellulosic materials (Strlič et al., 2015), represents a plot of lines connecting points of equal permanence, defined as the ratio of the rate of degradation at a given combination of $T, \mathrm{RH}$, and canvas $\mathrm{pH}$, vs. the rate of degradation at $20^{\circ} \mathrm{C}, 50 \% \mathrm{RH}$, and $\mathrm{pH}$ 5.1. This value of $\mathrm{pH}$ represents the average $\mathrm{pH}$ of canvases in the collection, while the values of $T$ and $\mathrm{RH}$ represent typical values for exhibition spaces, as adopted by Sebera (Sebera, 1994).

The isoperm plot allows us to estimate environmental conditions at which the permanence of an average canvas will be higher or lower than at $20^{\circ} \mathrm{C}$, $50 \% \mathrm{RH}$, where the permanence is arbitrarily set as

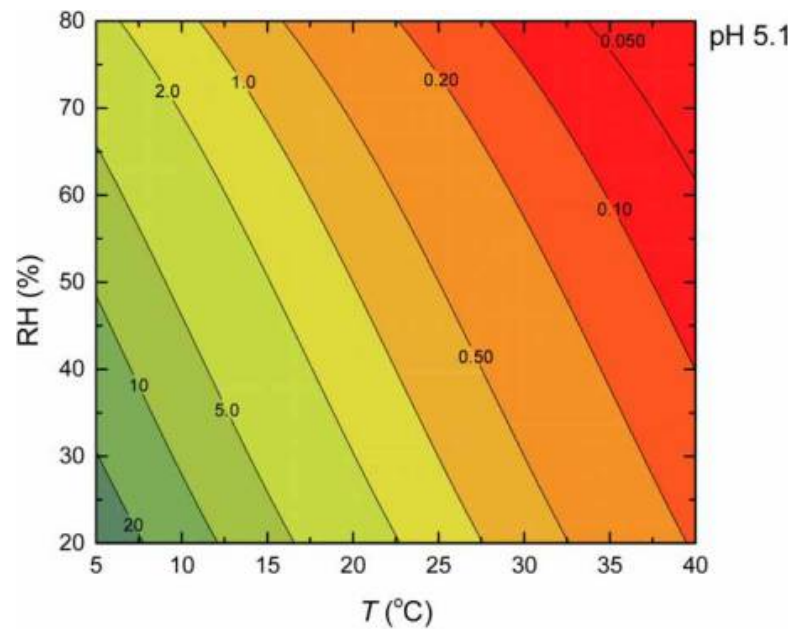

Figure 2 The isoperm plot for MNAC canvases, taking the average $\mathrm{pH}$ of the 31 surveyed canvases (and $20^{\circ} \mathrm{C} / 50 \% \mathrm{RH}$ ) as the reference permanence conditions.

1 (Fig. 2). Thus, the isoperm is useful to compare the suitability of various display or storage environments in relation to canvas degradation, but does not allow us to assess the following:

- The effect of environmental fluctuations, affecting material contraction/expansion and the associated crack formation/growth, or adhesion of layered structures

- The expected time until the MNAC canvases will become 'very fragile'

The former would need to be assessed using a dose-response function describing crack growth and delamination of paint layers as a function of $\mathrm{RH}$ or temperature fluctuations, which is not the purpose of this work. The latter, however, requires us to introduce the concept of threshold DP, i.e. DP at which canvases become unfit for manual handling, i.e. they become 'very fragile'.

\section{Canvas isochrones}

In our previous work (Oriola et al., 2011), we have shown that the category of canvases classified as 'very fragile' represents canvases with $\mathrm{DP}<600$, which could thus be taken as a suitable threshold DP for this category. This is a conservative threshold value, as it represents the upper limit of the 'very fragile' category: if a canvas was assessed as a borderline 'very fragile' canvas, at least half of the assessors actually thought it did not belong to the most fragile category.

A less conservative threshold would reflect a higher level of agreement between assessors. At DP 400, $80-100 \%$ of conservators-assessors agreed that the canvas should be categorised in the unfit category. Given that it has been shown that at DP 250 cellulosic fibres lose all mechanical properties (Shroff \& Stannett, 1985), DP 400 represents the median DP of 

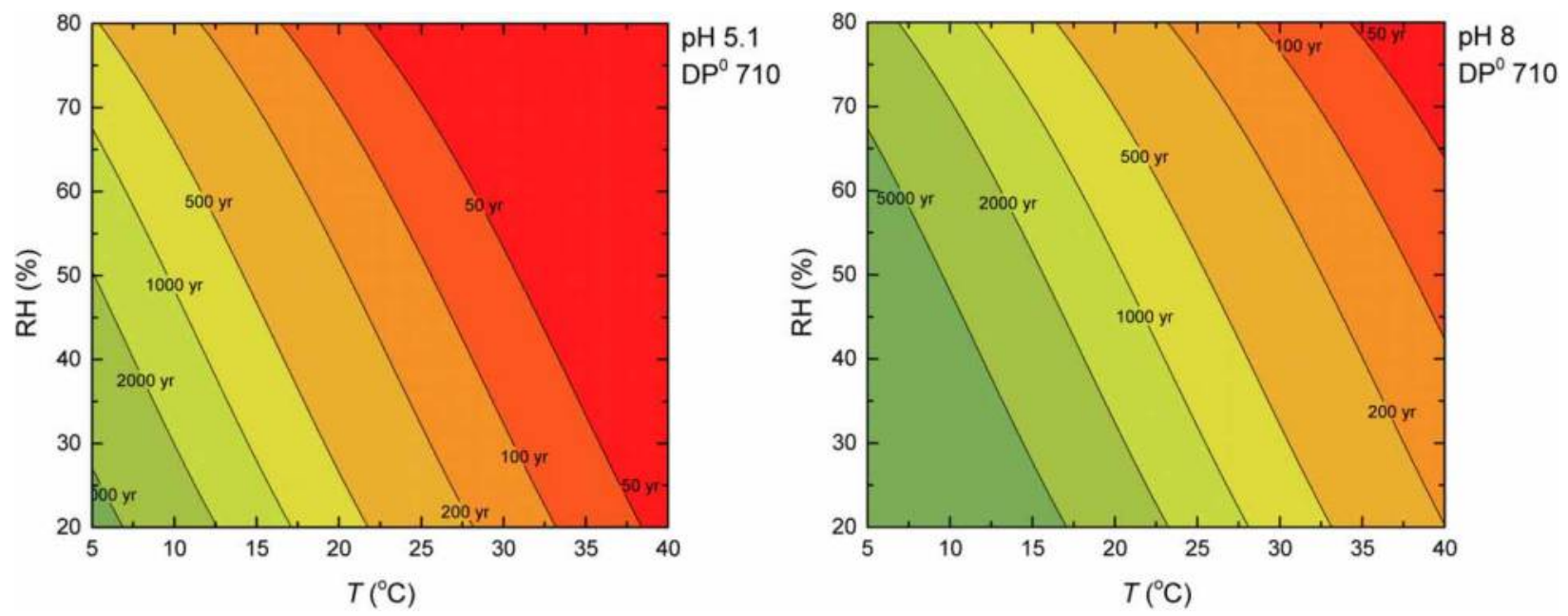

Figure 3 Isochrone plots for the average MNAC painting canvas (starting pH 5.1 and DP 710) at various environmental conditions (left), and assuming the $\mathrm{pH}$ of these canvases is increased to 8 by deacidification (right).

the 'very fragile' category, and thus a more suitable fitness threshold than its upper limit. We therefore propose DP 400 as the threshold DP in the calculations of useful lifetime of painting canvases.

With this threshold, and using the Collections Demography dose-response function, it is now possible to calculate isochrones, i.e. contour diagrams linking points of equal expected remaining lifetime for painting canvases in the collection of MNAC (Fig. 3). We have taken the average $\mathrm{pH}$ (5.1) and average DP (710) of the 31 surveyed canvases as the starting point in these calculations, and DP 400 as the endpoint.

The isochrone plot in Fig. 3 (left) shows that at Sebera's reference environmental conditions of $20^{\circ} \mathrm{C}$ and $50 \% \mathrm{RH}$, the average MNAC canvas will become 'very fragile' in $\sim 220$ years. Given that the average environmental conditions in MNAC galleries are $21{ }^{\circ} \mathrm{C}$ and $58 \% \mathrm{RH}$, this period of time is reduced to $\sim 140$ years. This is a reasonable prediction, if we take into account that the similar canvases at the Teatre-Museu Dalí were in average 40 years younger and had an average DP higher by $\sim 290$ - here we need to note that the Dalí canvases are less acidic and that the ageing curve is an exponential one, i.e. it levels off at longer ageing times.

Whether or not the average expected time until loss of fitness is a concern is a matter for discussion and needs to take into account the frequency of use of these canvases (e.g. travel to exhibitions) and their value other than utility, such as rarity, artistic, or historical value. In a recent assessment of a suitable longterm planning horizon for collections of objects of no ascribed exceptional value (Dillon et al., 2013), the horizon of 500 years for preventive conservation management was considered suitable, on the basis of a questionnaire distributed among visitors to a number of large archives and libraries in the UK and the
USA. Compared to this planning horizon, a lower storage temperature of ca. $15^{\circ} \mathrm{C}$ would be suitable, while maintaining the same $\mathrm{RH}$ of $50 \%$. (Interestingly, the mean annual temperature in Barcelona is $15^{\circ} \mathrm{C}$ (Wikipedia, 2014) which indicates that a passive but humidity-controlled storage environment would suffice.)

On the other hand, cooling of a collection yearround is a very resource-intensive option. In Fig. 3 (right), the isochrone plot is shown for the same collection, yet assuming that it has been deacidified, i.e. the $\mathrm{pH}$ of the canvas has been increased to 8 . It is clear that by using this conservation intervention, it is possible to increase the period of time until loss of fitness considerably, to $\sim 1100$ years.

From the resource point of view, the cost-benefit analysis clearly shows that deacidification is preferable to cooling. However, ethical considerations also need to be taken into account. Deacidification would lead to loss of material integrity of the canvas (i.e. change of its chemical composition due to deacidification) and this needs to be weighed against the delayed risk of loss of integrity of the painted layer.

\section{Demography of the Museu Nacional d'Art de Catalunya collection}

With the data for the surveyed paintings at hand, it is now also possible to calculate the time needed for each individual object in this collection to degrade until it becomes 'very fragile', since we have access to the average $\mathrm{pH}$ and DP data for each object. Currently, four canvases have already reached this stage, i.e. $15 \%$ of the collection.

The resulting frequency plot, showing the predicted 'survival' rate binned into intervals of 50 years, shows a steadily decreasing curve, reflecting the spread of $\mathrm{pH}$ and DP values of canvases in the collection. The demographic plot is monotonic, which is a 


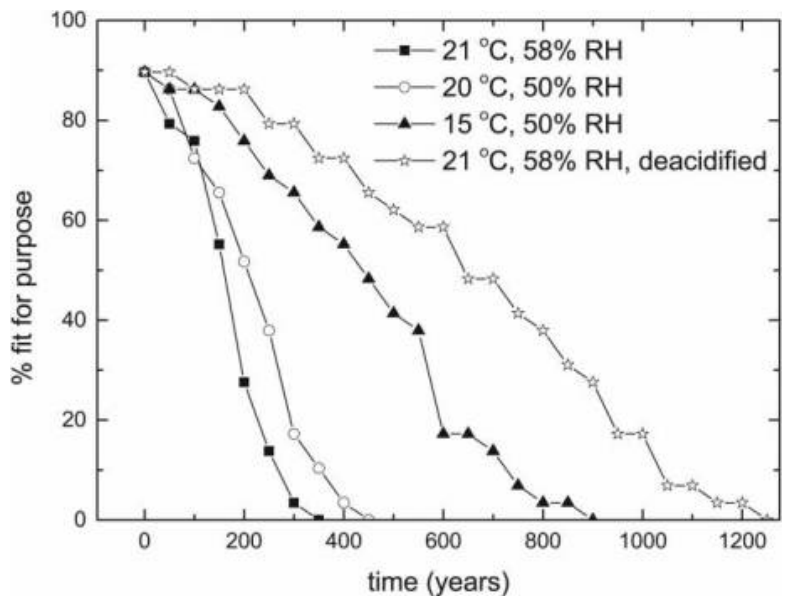

Figure 4 Demographic curve for the surveyed collection of MNAC paintings at the actual environmental conditions $\left(21^{\circ} \mathrm{C}, 58 \% \mathrm{RH}\right)$ as well as three hypothetic scenarios.

consequence of the narrow Gaussian distribution of $\mathrm{pH}$ values. This is in contrast with the demographic plot for library collections, which is usually doublebell shaped, reflecting the ageing of two populations of paper: acidic and alkaline.

The demographic plots (Fig. 4) can be used to evaluate the effect of different conservation management scenarios. These show how storage at a lower temperature or deacidification would affect the degradation of canvases: by storage in a passive (yet humidity controlled) environment at an average annual temperature of $15^{\circ} \mathrm{C}$, about $40 \%$ would survive 500 years without reaching the 'very fragile' state. On the other hand, by deacidification (increase of $\mathrm{pH}$ to 8) and storage at current environmental conditions, this number would increase to $60 \%$.

\section{The Woman in Hat and Fur Collar (Marie-Thérèse Walter)}

In 1937, Pablo Picasso painted the exceptional canvas The Woman in Hat and Fur Collar (Marie-Thérèse Walter), in the collection of MNAC (Doñate \& Llorens, 2007). As a separate case study, we measured the $\mathrm{pH}$ and DP of this canvas at 15 points, with the averages being $\mathrm{pH} 5.6 \pm 0.2$ and DP $1700 \pm 320$. Picasso painted it on a commercially primed plain weave canvas, of which one of the threads is cotton and the other one is a bast fibre (possibly linen).

The canvas of this painting is evidently in a good state, and would have been classified as 'good condition' in the survey referred to above (Oriola et al., 2011). As an example of a canvas in a 'good condition', it is of interest how quickly it will degrade in the future at various environmental conditions.

In Fig. 5, we present the isochrone plot for the canvas, showing that at the current average annual environmental conditions in MNAC galleries of

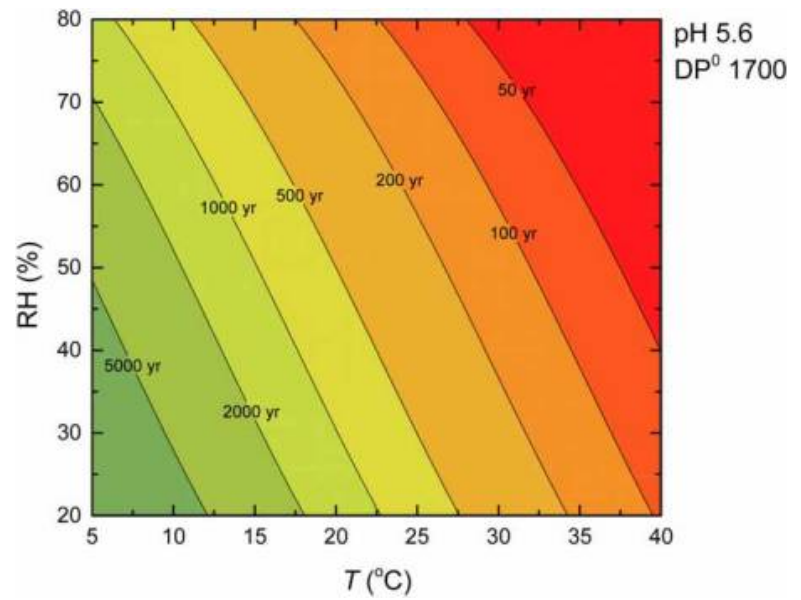

Figure 5 Isochrone plot calculated on the basis of the data measured for The Woman in Hat ....

$21{ }^{\circ} \mathrm{C}$ and $58 \% \mathrm{RH}$, it will take approximately 330 years for the canvas to degrade to the 'very fragile' state, while at Sebera's reference conditions $\left(20^{\circ} \mathrm{C}\right.$, $50 \% \mathrm{RH}$ ), this period would be ca. 500 years.

\section{Conclusions}

A survey of a limited number of canvases around the year $1900( \pm 10$ years $)$ was performed at the Museu Nacional d'Art de Catalunya. The selection of canvases (31) was such that they were all of natural origin (bast, jute, or cotton) and showed no evidence of previous conservation treatments. Using a near infrared spectrometric method based on multivariate data analysis, the degree of polymerisation and $\mathrm{pH}$ of these canvases was determined non-destructively and the data were analysed in a way that enabled informed conservation decision making. As a particular case study, we also surveyed Picasso's The Woman in Hat and Fur Collar (Marie-Thérèse Walter), from 1937.

The average $\mathrm{pH}$ of the surveyed canvases was determined to be $5.1 \pm 0.4$ and the average DP was $710 \pm$ 260. These are low compared with new canvas, however, the period of time before they become fragile to the point where their handling becomes a risk to their mechanical integrity (loss of fitness) can still be managed using different conservation strategies. At the actual environmental conditions at the museum, the average canvas will become 'very fragile' in ca. 140 years.

On the basis of the survey data, we developed isochrones (plots linking points of equal time until loss of fitness) and demographic plots to explore the benefits, and costs, of different storage and display climates, and of canvas deacidification.

The paper examines the stability of canvas as the carrier of paint layers and therefore looks at longterm average environmental conditions. In order to computationally examine the stability of paint layers 
themselves as well, a suitable dose-response function yet needs to be developed.

\section{Acknowledgements}

This work has been possible thanks to financial support from the University of Barcelona and from Cost Action D42 (EU). Access to the paintings was made possible thanks to Mireia Mestre, Head of the Conservation Department of the Museu Nacional d'Art de Catalunya (Barcelona).

\section{References}

Brimblecombe, P. \& Grossi, C.M. 2009. Millennium-long damage to building materials in London. Science of the Total Environment, 407: 1354-61

Dillon, C., Lindsay, W., Taylor, J., Fouseki, K., Bell, N. \& Strlič, M 2013. 'Collections Demography: Stakeholders' Views on the Lifetime of Collections'. In: J. Ashley-Smith, A. Burmester \& M. Eibl, eds. Climate for Collections Conference, Munich, Doerner Institut, 7-9 November 2012, Postprints. London: Archetype, pp. 45-58.

Doñate, M. \& Llorens, E. 2007. Picasso. Barcelona: Museu Nacional d'Art de Catalunya.

Fenech, A., Dillon, C., Ntanos, K., Bell, N., Barrett, M. \& Strlič, M. 2013. Modelling the Lifetime of Colour Photographs in Archival Collections. Studies in Conservation, 58: 107-16.

Menart, E., De Bruin, G. \& Strlič, M. 2014. Effects of $\mathrm{NO}_{2}$ and Acetic Acid on the Stability of Historic Paper. Cellulose, 21: 3701-13.

Oriola, M., Campo, G., Cséfalvayová, L., Odlyha, M., Možir, A. \& Strlič, M. 2011. Non-destructive Condition Assessment of Painting Canvases Using Near Infrared Spectroscopy. In: 16th Triennial Conference, Lisbon, 19-23 September 2011 Lisboa: ICOM-CC, pp. 1-8.

Oriola, M., Campo, G., Možir, A., Nualart-Torroja, A., RuizRecasens, C. \& Strlič, M. 2012. pH and DP Studies of Painting Canvases. In: Before, After...Instead of Restoration. Proceedings of the VI International Congress Colour and Conservation 2012, Parma 16-17 November 2012. Saonara: Il Prato, pp. 201-7.
Oriola, M., Možir, A., Garside, P., Campo, G., Nualart-Torroja, A., Civil, I., Odlyha, M., Cassar, M. \& Strlič, M. 2014. Looking Beneath Dalí's Paint: Non-destructive Canvas Analysis. Analvtical Methods, 1: 86-96.

PAS 198: 2012. Specification for Environmental Conditions for Cultural Collections. London: British Standards Institute.

Poggi, G., Toccafondi, N., Melita, L.N., Knowles, J.C., Bozec, L., Giorgi, R. \& Baglioni, P. 2013. Calcium Hydroxide Nanoparticles for the Conservation of Cultural Heritage: New Formulations for the Deacidification of Cellulosebased Artifacts, Applied Physics A: Materials Science and Processing, 114(3): 685-693.

Richardson, E., Martin, G., Wyeth, P. \& Zhang, X. 2008. State of the Art: Non-invasive Interrogation of Textiles in Museum Collections. Microchimica Acta. Springer Wien, 162: 303-12.

Sebera, D.K. 1994. Isoperms. An Environmental Management Tool. Full text accessed from 05 January 2014: http://cool.conserva tion-us.org/byauth/sebera/isoperm/index.html.

Seves, A.M., Sora, S., Scicolone, G., Testa, G., Bonfatti, A.M. Rossi, E. \& Seves, A. 2000. Effect of Thermal Accelerated Ageing on the Properties of Model Canvas Paintings. Journal of Cultural Heritage, 1: 315-22.

Shroff, D.H. \& Stannett, A.W. 1985. A Review of Paper Aging in Power Transformers. IEEE Proceedings, 132: 312-8.

Strlič, M. \& Kolar, J. eds. 2005. Ageing and Stabilisation of Paper. Ljubljana: National and University Library.

Strlič, M., Thickett, D., Taylor, J. \& Cassar, M. 2013. Damage Functions in Heritage Science. Studies in Conservation, 58: 80-7.

Strlič, M., Bell, N., Fouseki, K. Xue, J., Dillon, C., Menart, E., Ntanos, K., Lindsay, W., Grossi, C., Thickett, D., France, F. \& De Bruin, G. 2015. Damage Function for Historic Paper. Part II: Dose-Response Function. Heritage Science, in press.

Trafela, T., Strlič, M., Kolar, J., Lichtblau, D.A., Anders, M., Pucko Mencigar, D. \& Pihlar, B. 2007. Non-destructive Analysis and Dating of Historical Paper Based on IR Spectroscopy and Chemometric Data Evaluation. Analvtical Chemistrv, 79: 6319-23.

Wikipedia, http://en.wikipedia.org/wiki/Climate_of_Barcelona, accessed 05 January 2014.

Zou, X., Uesaka, T. \& Gurnagul, N. 1996. Prediction of Paper Permanence by Accelerated Aging. 1. Kinetic Analysis of the Aging Process. Cellulose, 3: 243-67. 
Supplementary material 1

List of the 31 painting canvases from Museu Nacional d'Art de Catalunya, Barcelona, Spain (MNAC) used in the research.

\begin{tabular}{|c|c|}
\hline Cat. No. & Author, Title, date \\
\hline 004.038 & Ramon Casas, Estudi, circa 1899 \\
\hline 004.040 & Ramon Casas, Le Sacré Coeur, Montmartre, 1891 \\
\hline 004.033 & Ramon Casas, Pati de l'antiga presó de Barcelona, 1894 \\
\hline 069.042 & Ramon Casas, Dona en un interior, 1890 \\
\hline 011.382 & Ramon Casas, Estudi del natural per al retrat del rei Alfons XIII, 1904 \\
\hline 010.901 & Ramon Casas, Plen air, 1890-1891 \\
\hline 069.023 & Francesc Gimeno, Llegint el diari, 1886 \\
\hline 113.503 & Juli González, Dona rentant-se, 1912-1913 \\
\hline 004.005 & Joan Llimona, La novícia, 1898 \\
\hline 004.006 & Joan Llimona, Pasturant, 1901 \\
\hline 004.630 & Joaquim Mir, Paisatge (Maspujols. Camp de Tarragona), 1907-1910 \\
\hline 004.631 & Joaquim Mir, Paisatge, 1907-1910 \\
\hline 042.090 & Joaquim Mir, Hort amb casa de pagès \\
\hline 065.291 & Mela Mutermilch, Retrat de J. Dalmau, 1911 \\
\hline 010.921 & Isidre Nonell, Gitana jove, 1903 \\
\hline 065.620 & Isidre Nonell, Gracieta, 1907 \\
\hline 010.926 & Isidre Nonell, La Pilar, 1907 \\
\hline 004.660 & Isidre Nonell, Júlia, 1908 \\
\hline 065.623 & Isidre Nonell, Lassitud, 1910 \\
\hline 214.090 & Pablo Picasso, Dona amb barret i coll de pell (Marie-Thérèse Walter), 1937 \\
\hline 004.093 & Marià Pidelaserra, Un dia d'hivern en el jardí del Luxemburg, 1900 \\
\hline 043.719 & Marià Pidelaserra, Vall de Querol, 1897 \\
\hline 004.003 & Santigo Rusiñol, La riallera, 1894 \\
\hline 040.095 & Santigo Rusiñol, Jardí de Montmartre, 1890-1891 \\
\hline
\end{tabular}




\begin{tabular}{|l|l|}
\hline 045.267 & Santigo Rusiñol, Entrada al parc del Moulin de la Galette, 1891 \\
\hline 063.980 & Santigo Rusiñol, Retrat de nen, 1893-1895 \\
\hline 004.048 & Santigo Rusiñol, "La Butte", 1892 \\
\hline 039.143 & Joaquim Sunyer, Gitanes, 1906 \\
\hline 039.144 & Joaquim Sunyer, Gitanes, 1907 \\
\hline 010.588 & Joaquim Vayreda, Nens jugant (estudi), 1889 \\
\hline 010.593 & Joaquim Vayreda, Camp de fajol (apunt), 1892 \\
\hline 010.589 & Joaquim Vayreda, La roureda, 1892 \\
\hline
\end{tabular}

